\title{
Where is genetic medicine headed? Exploring the perspectives of Canadian genetic professionals on future trends using the Delphi method
}

\author{
Kennedy Borle (D ${ }^{1}$, Nicola Kopac ${ }^{1}$, Nick Dragojlovic (D) ${ }^{1}$, Elisabet Rodriguez Llorian ${ }^{1}$, Jan M. Friedman ${ }^{2,3}$, GenCOUNSEL Study, \\ Alison M. Elliott $\mathbb{D}^{2,3,4}$ and Larry D. Lynd (iD) ${ }^{1,5 \times}$
}

(c) The Author(s), under exclusive licence to European Society of Human Genetics 2021

\begin{abstract}
Driven by technological and scientific advances, the landscape of genetic medicine is rapidly changing, which complicates strategic planning and decision-making in this area. To address this uncertainty, we sought to understand genetic professionals' opinions about the future of clinical genetic and genomic services in Canada. We used the Delphi method to survey Canadian genetic professionals about their perspectives on whether scenarios about changes in service delivery and the use of genomic testing would be broadly implemented in their jurisdiction by 2030 . We conducted two survey rounds; the response rates were $32 \%$ (27/ $84)$ and $67 \%$ (18/27), respectively. The most likely scenario was the universal use of noninvasive prenatal screening. The least likely scenarios involved population-based genome-wide sequencing for unaffected individuals. Overall, the scenarios perceived as most likely were those that have existing evidence about their benefit and potential medical necessity, whereas scenarios were seen as unlikely if they involved emerging technologies. Participants expected that the need for genetic healthcare services would increase by 2030 owing to changes in clinical guidelines and increased use of genome-wide sequencing. This study highlights the uncertainty in the future of genetic and genomic service provision and contributes evidence that could be used to inform strategic planning in clinical genetics.
\end{abstract}

European Journal of Human Genetics (2022) 30:496-504; https://doi.org/10.1038/s41431-021-01017-2

\section{INTRODUCTION}

The landscape of clinical genetic and genomic services (genetic testing, counseling, and consultations) is rapidly changing. Drivers of this change include advances in technology, changes in the clinical utility of genetic information, and service delivery models that are being used to increase the capacity of the genetic workforce [1-3]. In particular, advances in genomic testing technologies have enabled the development and clinical implementation of increasingly comprehensive tests [4] transforming genetic services over the past 15 years. For example, genomewide sequencing (GWS; exome or genome sequencing) has increased the diagnostic yield for individuals undergoing diagnostic genetic testing far beyond that of multigene panels or tiered single gene approaches. In a study comparing diagnostic approaches in children with suspected genetic disorders, diagnostic yield with GWS was $41 \%$ compared with $24 \%$ with conventional genetic testing [5]. In some clinical areas, including hereditary cancer, there has been a steady growth in referral volumes and testing utilization, owing in part to a growing evidence base supporting the benefits of genetic testing and counseling [6]. Finally, substantial changes in service delivery models have increased the capacity of the clinical genetics workforce [1, 2], including the use of decision aids for genetic testing [7], high-throughput telegenetics services [8], and artificial intelligence-driven chat bots [9].

This transformation in clinical genetics makes strategic planning and healthcare policy development in this area extremely challenging. In particular, the expansion of services and eligibility criteria introduces a major source of uncertainty into projections of the future need for services, which as a result cannot be easily extrapolated from current trends. This is problematic because determining eligible patient populations and levels of service are critical steps in needs-based health human resource planning [10]. Indeed, this challenge is compounded by a number of debates within the genetic community about the appropriateness of expanding eligibility for services in areas such as hereditary cancer $[11,12]$, population screening applications [13, 14], and preconception carrier screening [15].

One approach to addressing the uncertainties in strategic planning created by disjunctures in eligibility criteria and technology is to seek out a range of expert opinions that can be used to evaluate the plausibility of a range of possible futures [16-19]. In the present study, we sought to characterize possible changes over the next decade by using the Delphi method to

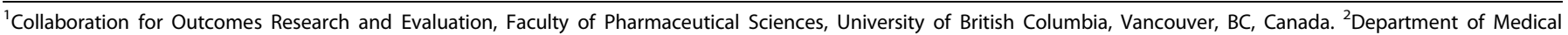

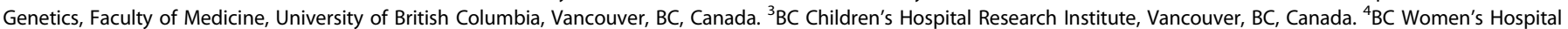

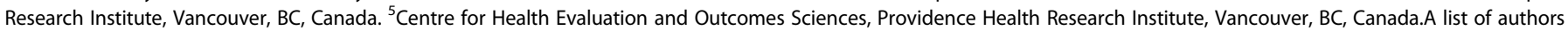
and their affiliations appears at the end of the paper. A list of members and their affiliations appears in the Supplementary Information. ${ }^{\circledR}$ email: larry.lynd@ubc.ca 
elicit the perspectives of experts on the future of genetic service provision in Canada. The results can be used directly to inform strategic planning for genetic medicine in Canada, and because most of the transformation of genetic medicine is driven by technological and scientific developments, these findings may also be of broad applicability to other high-income jurisdictions [6].

\section{MATERIALS AND METHODS}

We used a two-round Delphi study to build agreement within Canadian stakeholders' perceptions on a range of scenarios regarding the provision of clinical genetic and genomic services in their jurisdiction by the year 2030. This study was approved by the University of British Columbia Research Ethics Board as a sub-study of the GenCOUNSEL research project (REB ID: H19-00427; https://www.bcchr.ca/GenCOUNSEL).

\section{The Delphi method}

The survey-based Delphi method is an iterative process in which a series of surveys is administered to experts in the field to elicit opinions and develop consensus about a topic [20]. It has been shown to be an effective methodology for solving complex problems, generating evidence for phenomena that are not well understood, anticipating future trends, and exploring areas with high levels of controversy or uncertainty [21, 22]. The survey is revised in each iteration to add items based on participant responses in previous rounds, and feedback is given to participants between rounds to show how their responses compared to the group responses. The Delphi method has previously been used to elicit expert opinions in genetic medicine [23-25]. Our survey was administered online through REDCap [26], and participants' identities were not revealed to each other.

\section{Participant recruitment and retention}

A list of potential participants was compiled of individuals working in clinical leadership roles in all publicly funded genetic clinics in Canada (as determined through the Canadian Association of Genetic Counsellors "Find a Clinic" web tool) and supplemented with targeted web searches to find individuals who worked in laboratory and research settings and did not limit our search to those affiliated with an academic medical center. Since healthcare is primarily funded provincially, we purposively sampled participants from every province to capture potential inter-provincial differences. Eighty-six potential participants were contacted by email in May 2020 with a study invitation letter that was used for snowball sampling and to assess preferred timing for initiation of the study given the additional demands placed on the genetic community by the COVID19 pandemic.

We sent Survey \#1 to 84 individuals. It was launched on 23 June 2020, and was open for 4 weeks. Individualized feedback was provided to the respondents after the first survey (see Supplementary Materials for an example). Survey \#2 was launched on 24 September 2020, and was also open for four weeks. Participants were sent two reminders during each survey period. We provided participants who completed both rounds of the survey with a $\$ 10$ coffee gift card.

\section{Survey development}

The questionnaire was developed based on findings from two scoping reviews about genetic services utilization and the workforce performed by members of the study team $[2,6]$. The survey was broken down into four content categories: prenatal and newborn screening, oncology, other suspected genetic disorders, and service delivery and technology. We used a combination of Likert-style questions assessing the perceived likelihood of a scenario, percent-style slider questions to assess the proportion of individuals for whom a given scenario would be applicable, free-text boxes, and demographic questions. The Likert-style response options ranged from 1 to $4(1=$ very unlikely to $4=$ very likely), plus an "I don't know" option. The survey was pilot tested with one genetic counselor and one clinical geneticist who participated in a cognitive interview while completing the questionnaire. The final version of Survey \#1 is included in the Supplementary Materials. Survey \#2 included all items from Survey \# 1 that did not meet consensus (as described below) plus additional questions that were added based on the open-ended responses on Survey \#1.

\section{Analysis}

The Delphi method typically uses two measures of an agreement to achieve the study goals. Stability is a measurement of item-level consistency of responses between survey rounds, and consensus indicates whether the majority of respondents chose the same response for a given item. There are no best practices for operationalizing agreement in the literature, however, stability is thought to be a more reliable indicator than consensus [20]. We used stability as our primary measure of agreement and used consensus as a secondary measure to remove items from one survey round to the next.

There is no standard way to calculate the stability, but one commonly used approach is to set a threshold for observed changes in the mean group response from one round to the next (e.g., $<0.5$ or 1.0 change in the mean score). In our study, to be able to apply the same threshold for the Likert scale and percent-style questions, our threshold was set such that more than $15 \%$ change in the mean scores between rounds would indicate stability $[27,28]$. Because the $15 \%$ threshold has not been widely used in the literature, we also examined stability using hypothesis testing (Wilcoxon signed-rank test and paired-samples $t$ test) to determine whether the mean response for any item was significantly different between rounds [29]. We used a Bonferroni correction to account for multiple comparisons and set statistical significance at $p<0.002$. We applied these two stability criteria independently, and an item was determined to be stable only if stability was met on both measures.

Consensus was defined as occurring when $>75 \%$ of respondents chose the same Likert scale response option or were within $10 \%$ on the slider scale questions. Using $75 \%$ as the Likert scale threshold was informed by a systematic review of Delphi studies where $75 \%$ agreement was the median value [30]. The decision to use a $10 \%$ range for the percent-style questions was a practical decision since respondents could choose any number on the scale from 1 to 100 . We included all responses for Survey \#1 in the agreement calculations, not only those from participants who also completed Survey \#2.

Our study protocol called for the termination of the study after three rounds at most, or earlier if consensus and/or stability of most items had been reached after two rounds. We excluded the responses to the percent questions from one participant because they were an outlier. We used descriptive statistics to report the demographic characteristics of participants between rounds to determine whether there was drop-off of participants in specific demographic groups, and combined groups where numbers were low. We analyzed the open-ended text feedback using thematic content analysis. Two study team members independently coded open-ended text and then grouped topics into themes, comparing for agreement and resolving disagreement through consensus. The purpose of the qualitative analysis of the open-ended feedback was to identify additional items to add to Survey \#2 [31].

\section{RESULTS}

\section{Response rates}

We sent the study invitation letter to 86 individuals and recruited one additional invitee through snowball sampling. We subsequently invited 84 individuals to complete Survey \#1,32\% (27/84) of whom completed at least one question. We sent Survey \#2 to the 27 participants who completed at least some part of Survey $\# 1$, and $67 \%$ (18/27) of that group responded to Survey \#2. The response rates are outlined in Fig. 1.

\section{Demographics}

Participant demographics for both rounds are summarized in Table 1. Demographic questions were only asked on Survey \#1 and were completed by $89 \%$ (24/27) of participants. The majority of participants were women (Survey \#1: 83\%, 20/24, Survey \#2: $88 \%, 14 / 16$ ) and genetic counselors (Survey $\# 1: 63 \%, 15 / 24$, Survey \#2: 75\%, 12/16) or physicians (Survey \#1: 29\%, 7/24, Survey \#2: $19 \%, 3 / 16$ ). Half of the participants (Survey \#1: 50\%, 12/24, Survey $\# 2: 50 \%, 8 / 16$ ) reported more than one professional role including management, educational, or research-focused positions. There were participants from across Canada, with the highest representation from British Columbia (Survey \#1: 42\%, 10/24, Survey \#2: $50 \%, 8 / 16)$; however, there were no participants from any of the three Canadian territories. The most common primary areas of 


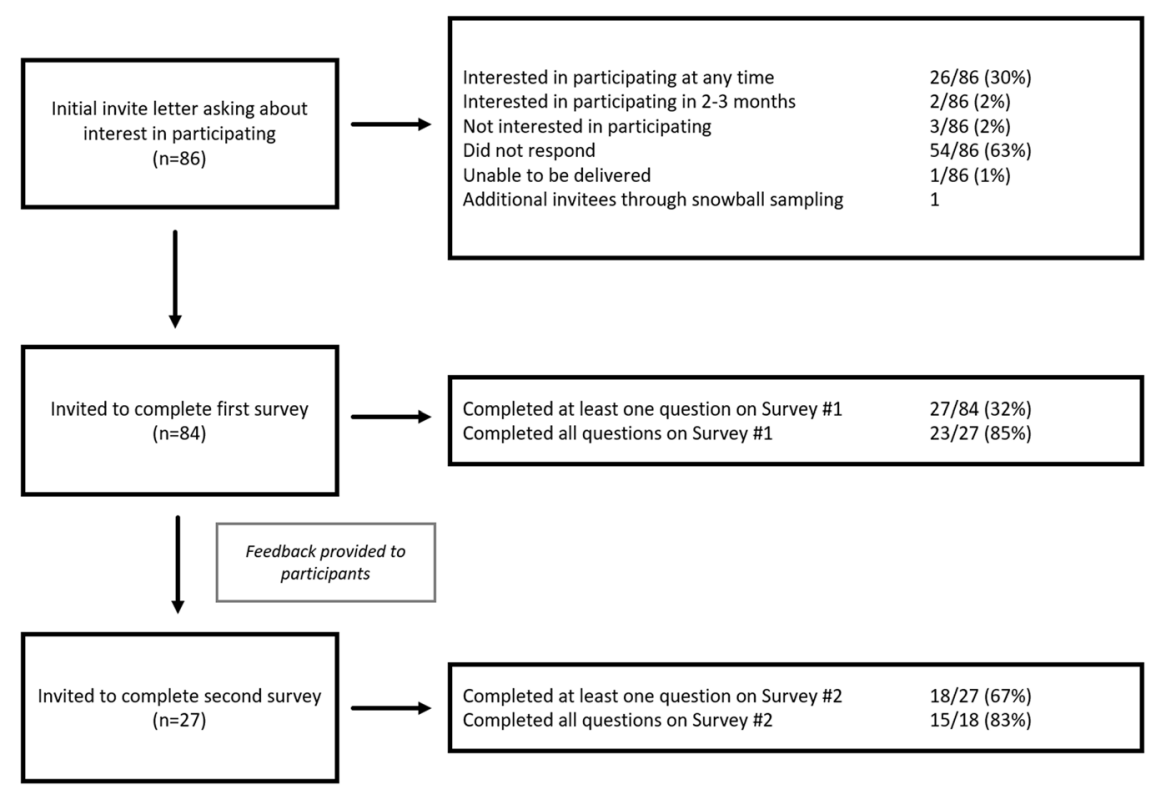

Fig. 1 Participation flow chart with response rates. Summary of the recruitment process and response rates for the Delphi study. We invited all individuals who did not decline the initial invitation letter to complete Survey \#1. Feedback was sent to all participants who completed Survey \#1. We only sent Survey \#2 to those who completed at least one question on Survey \#1.

practice were cardiology (Survey \#1: 17\%, 4/24, Survey \#2: 19\%, 3/ 16) and prenatal (Survey \#1: 13\%, 3/24, Survey \#2: 19\%, 3/16). Many participants indicated that they work in multiple clinical areas (Survey \#1: 58\%, 14/24, Survey \#2: 44\%, 7/16).

\section{Stability and consensus}

After Survey \#2, 88\% (23/26) of the repeated items had reached stability and we concluded that a third-round was not likely to increase stability and terminated the study. The results from the survey are summarized in Tables 2, 3, and Supplementary Table 1. Only one Likert-style item did not show stability, as the mean changed by $>15 \%$; however, this difference was not statistically significant. The mean scores on two percent-style questions changed by $>15 \%$, however, these differences were also not statistically significant (Supplementary Table 1). There were only two items for which consensus was reached (i.e., $>75 \%$ of individuals chose the same Likert scale option), one in Survey \#1 and one in Survey \#2 (Table 2; Table 3; Supplementary Table 1). There was no consensus reached on any of the percent-style questions. The open-ended text questions were analyzed with the goal of adding additional concepts to Survey \#2 and these responses were not assessed for agreement.

\section{Summary of scenarios by content area}

Responses to questions in each content area are summarized in Tables 2 and 3, and Supplementary Table 1. The values reported in the text report respondents who indicated that a particular scenario was likely (somewhat or very likely) and are drawn from Survey \#2 unless otherwise specified to reflect the point at which responses met stability criteria.

\section{Prenatal and newborn medicine}

Participants responded to five Likert questions about changes to prenatal, preconception, and newborn screening by the year 2030. The scenario deemed most likely was the use of noninvasive prenatal screening (NIPS, i.e.: cell-free DNA (cfDNA) screening) as a first-line prenatal screening test for aneuploidy $(n=17,95 \%$ chose somewhat or very likely). Sixty-one percent $(n=11)$ of respondents thought that expansion of NIPS to include genome-wide screening for copy number variants was likely, and only 39\% ( $n=$
7) thought that expansion to include monogenic conditions was likely. Routinely offering expanded carrier screening to all couples planning a pregnancy was seen as likely by $66 \%(n=12)$ of respondents. The least likely scenario was the addition of GWS to newborn screening ( $24 \%, n=5$ chose somewhat or very likely).

\section{Oncology}

Participants responded to four Likert scenario questions and four percent-style questions about the utilization of genetics in oncology settings in the year 2030. Most participants thought it was likely that eligibility guidelines for genetic counseling/testing would expand for individuals affected with cancer $(72 \%, n=13$ chose somewhat or very likely), but fewer thought it was likely that eligibility guidelines for unaffected family members would expand to include all types of cancer $(53 \%, n=10$ responded somewhat or very likely). Within the percent-style questions, respondents estimated that an average of 59\% (range: $25-100 \%$ ) of individuals with cancer will receive germline pharmacogenetic testing by 2030. Participants expected that the proportion of patients who will have genetic testing through GWS would be $48 \%$ (range: $15-97 \%$ ) for those undergoing tumor testing and $32 \%$ (range: $10-80 \%)$ for those undergoing testing for hereditary cancer. Participants expected that $32 \%$ (range: 20-50\%) of individuals with any type of cancer would receive germline genetic testing.

\section{Suspected genetic disorders}

Participants answered six Likert scenario questions and one percent-style question about the future utilization of genetic and genomic services in suspected genetic disorders by the year 2030 . The most likely scenario was the routine offering of rapid GWS for patients with suspected genetic disease in the neonatal and pediatric intensive care setting by 2030, which met the consensus condition on Survey \#2 with all experts considering this scenario likely $(n=17,100 \%)$. Participants reported that they thought broad substitution of chromosomal microarray (CMA) with genome sequencing was likely ( $n=16,94 \%$ responded likely) for individuals with neurodevelopment disorders. Eighty-eight percent $(n=15)$ perceived the substitution of multigene panels with GWS was likely for individuals with neurodevelopmental 
Table 1. Participant demographics.

\begin{tabular}{|c|c|c|}
\hline Characteristic & $\begin{array}{l}\text { Survey } 1(n=24)^{a} \\
\text { Number of } \\
\text { participants (\%) }\end{array}$ & $\begin{array}{l}\text { Survey } 2(n=16)^{b} \\
\text { Number of } \\
\text { participants }(\%)\end{array}$ \\
\hline \multicolumn{3}{|l|}{ Gender } \\
\hline Woman & $20(83)$ & $14(88)$ \\
\hline Man & $3(13)$ & $2(13)$ \\
\hline Prefer not to say & $1(4)$ & 0 \\
\hline \multicolumn{3}{|l|}{ Profession* } \\
\hline Genetic counselor & $15(63)$ & $12(75)$ \\
\hline Medical Doctor & $7(29)$ & $3(19)$ \\
\hline $\mathrm{PhD}$ geneticist & $2(8)$ & 0 \\
\hline Laboratory geneticist $^{\mathrm{c}}$ & $2(8)$ & $1(6)$ \\
\hline \multicolumn{3}{|l|}{ Experience } \\
\hline $1-10$ years & $4(17)$ & $4(25)$ \\
\hline $10-20$ years & $10(42)$ & $4(25)$ \\
\hline$>20$ years & $8(33)$ & $6(38)$ \\
\hline NR & $2(8)$ & $2(13)$ \\
\hline \multicolumn{3}{|l|}{ Province ${ }^{*}$} \\
\hline British Columbia & $10(42)$ & $8(50)$ \\
\hline $\begin{array}{l}\text { Prairies (Alberta, } \\
\text { Saskatchewan, Manitoba) }\end{array}$ & $6(25)$ & $3(19)$ \\
\hline Ontario & $2(8)$ & $2(13)$ \\
\hline Quebec & $4(25)$ & $2(19)$ \\
\hline $\begin{array}{l}\text { Maritimes (Nova Scotia, New } \\
\text { Brunswick, Newfoundland, } \\
\text { Prince Edward Island) }\end{array}$ & $6(8)$ & $1(6)$ \\
\hline \multicolumn{3}{|l|}{ Type of institution* } \\
\hline Hospital/Medical Facility & $21(88)$ & $14(88)$ \\
\hline $\begin{array}{l}\text { Diagnostic } \\
\text { Laboratory-commercial/non- } \\
\text { academic }\end{array}$ & $1(4)$ & 0 \\
\hline $\begin{array}{l}\text { Diagnostic Laboratory-non- } \\
\text { commercial/academic }\end{array}$ & $2(8)$ & $2(13)$ \\
\hline University & $8(33)$ & $5(31)$ \\
\hline Other & $1(4)$ & $1(6)$ \\
\hline \multicolumn{3}{|l|}{ Primary area of clinical practice } \\
\hline General adult genetics & $2(8)$ & $2(13)$ \\
\hline Pediatrics & $1(4)$ & 0 \\
\hline Prenatal & $3(13)$ & $3(19)$ \\
\hline Cancer & $2(8)$ & $1(6)$ \\
\hline Cardiology & $4(17)$ & $3(19)$ \\
\hline Neurogenetics & $2(8)$ & $1(6)$ \\
\hline Metabolic disease & $3(13)$ & $1(6)$ \\
\hline Laboratory & $3(13)$ & $2(13)$ \\
\hline Public Health & $1(4)$ & $1(6)$ \\
\hline Pharmacogenetics & $1(4)$ & $1(6)$ \\
\hline $\begin{array}{l}\text { Not currently in clinical } \\
\text { practice }\end{array}$ & $2(8)$ & $1(6)$ \\
\hline \multicolumn{3}{|c|}{$\begin{array}{l}\text { aThree participants did not answer demographic questions on Survey \#1. } \\
\text { The percentages may not add up to } 100 \% \text { due to rounding and/or because } \\
\text { for some questions participants could choose more than one response. } \\
\text { b Two participants who responded to Survey \#2 did not answer } \\
\text { demographic questions. } \\
{ }^{c} \text { This category includes clinical molecular geneticists and clinical cytogen- } \\
\text { eticists. } \\
\text { *Participants could select more than one answer. }\end{array}$} \\
\hline
\end{tabular}

conditions. The proportion of respondents who thought that that the substitution of multigene panels with GWS was likely varied by the clinical area on which each item focused: $71 \%(n=12)$ for adult-onset neurological conditions, $64 \%(n=11)$ for cardiac conditions, and 59\% $(n=10)$ for vascular connective tissue disorders. Participants estimated that 58\% (range: 15-100\%) of pediatric patients with a suspected genetic disorder will be offered GWS as their first-line genetic investigation by 2030 .

\section{Service delivery and health technology}

Participants answered nine Likert scenario questions relating to service delivery and health technology in the first survey and eight questions in the second. On the first survey, consensus was reached for one item, publicly funded population-based GWS screening for unaffected individuals by 2030 was perceived to be very unlikely by $79 \%(19 / 24)$ of respondents. Similarly, few participants perceived patient-pay population-based GWS for unaffected individuals as likely $(12 \%, n=2)$. Fifty-three percent of participants $(n=9)$ thought legislative changes would allow genetic counselors to provide counseling independently in their province by 2030 , and $47 \%(n=8)$ thought it was likely that legislative changes would allow genetic counselors to order testing independently. Of note, those who thought these two scenarios were likely were not limited to genetic counselor respondents or limited to a particular geographical or clinical area. Responses about the likelihood that post-test counseling would be fully automated (e.g., by online education, decision aids, chat bots, etc.) were broken down by type of result as follows: negative/uninformative results $(53 \%, n=9$ chose somewhat or very likely), positive results $(47 \%, n=8$ chose somewhat or very likely), and variants of uncertain significance $(0 \%, n=0$ chose somewhat or very likely). In terms of automation for pre-test counseling, $47 \%(n=8)$ of respondents perceived this scenario as likely. Respondents estimated that by 2030 , an average of $11 \%$ (range: $0-30 \%$ ) of unaffected adults will receive population-based GWS for adult-onset disorders.

\section{DISCUSSION}

This is the first study of its kind to explore genetic professionals' perspectives about the future utilization of genetic and genomic services in Canada. Overall, scenarios for which the application in question is already being offered clinically in some settings or where there is existing evidence to support effectiveness were seen as likely. This includes the use of GWS in the neonatal intensive care unit [32], the routine use of carrier screening in preconception settings $[15,33]$, and the use of GWS as a first-line test for neurodevelopmental disorders [34]. Within the public healthcare system in Canada, funding decisions for genetic testing are often based on whether the genetic information would directly impact medical management [35]. It is possible that the perceived medical utility of certain scenarios led to these scenarios being seen as more likely.

In contrast, scenarios involving technology that is emerging or currently has little evidence of clinical utility were seen as unlikely. This includes scenarios about expanding the indications for prenatal screening using NIPS to include monogenic disorders and the use of GWS for newborn screening. These findings are consistent with other literature that shows that the value of genetic information may not be apparent if there is a lack of evidence about health benefits or if possible harms outweigh reproductive benefits [24,36]. However, despite being perceived by the majority as unlikely, $24 \%$ of respondents thought that the use of GWS for the newborn screening was likely by 2030, which also demonstrates the variability in responses and highlights the future uncertainty of service provision.

Participants were asked about the possibility of test substitution in different clinical settings. Possibilities included replacement of currently used genetic tests (multigene panels and CMA) with GWS (genome or exome sequencing)). Test substitution with GWS was perceived overall as likely in all clinical settings where it would be used for diagnosis of a possible genetic condition. Differences 


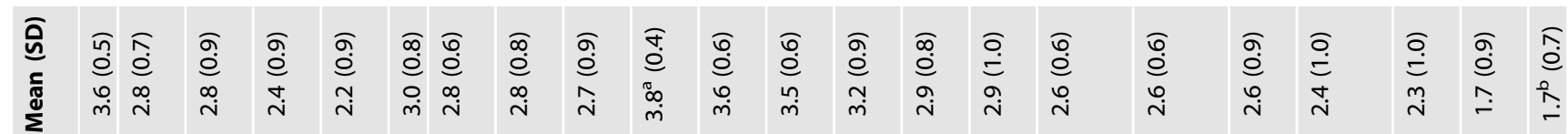

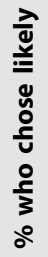

น

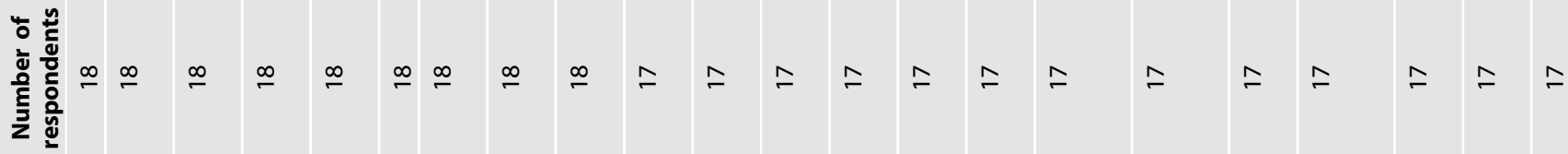

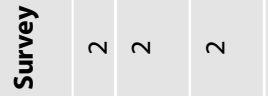

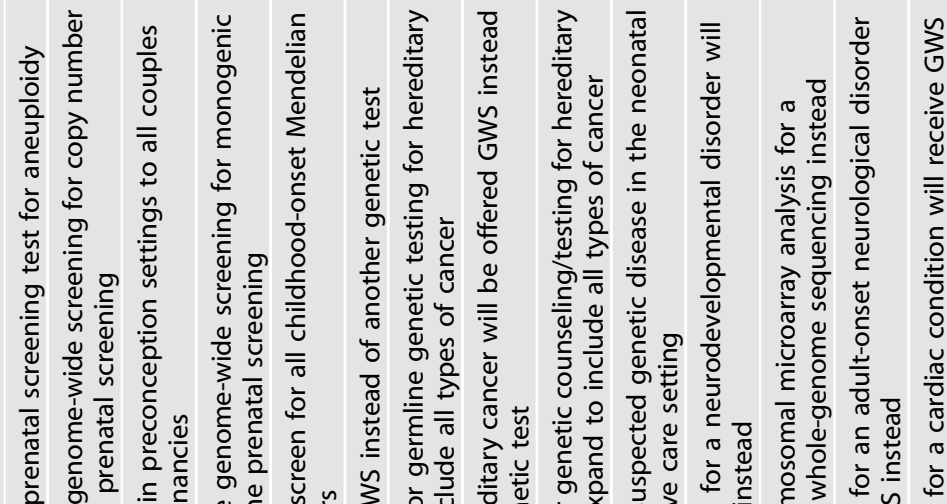

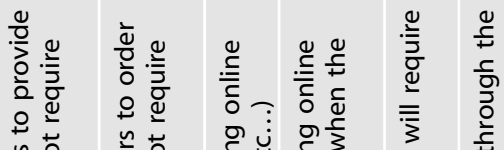

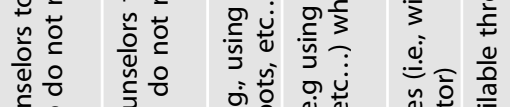

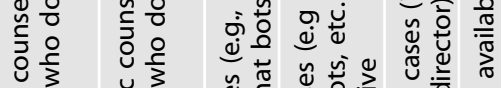

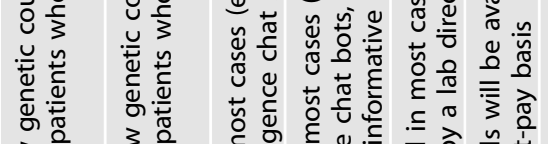

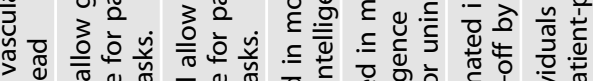
>

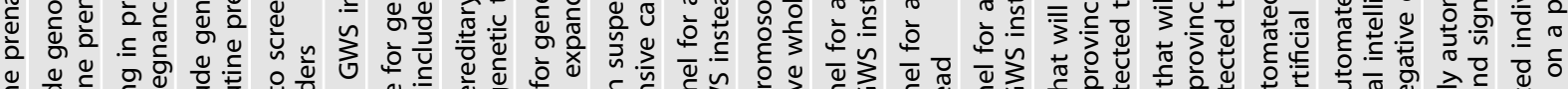

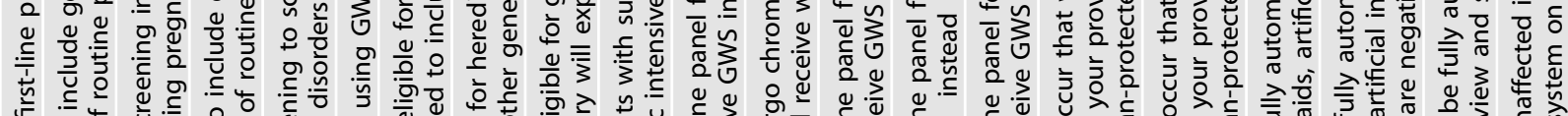

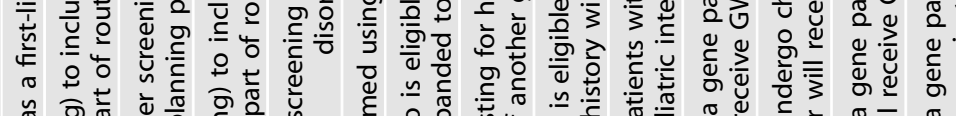

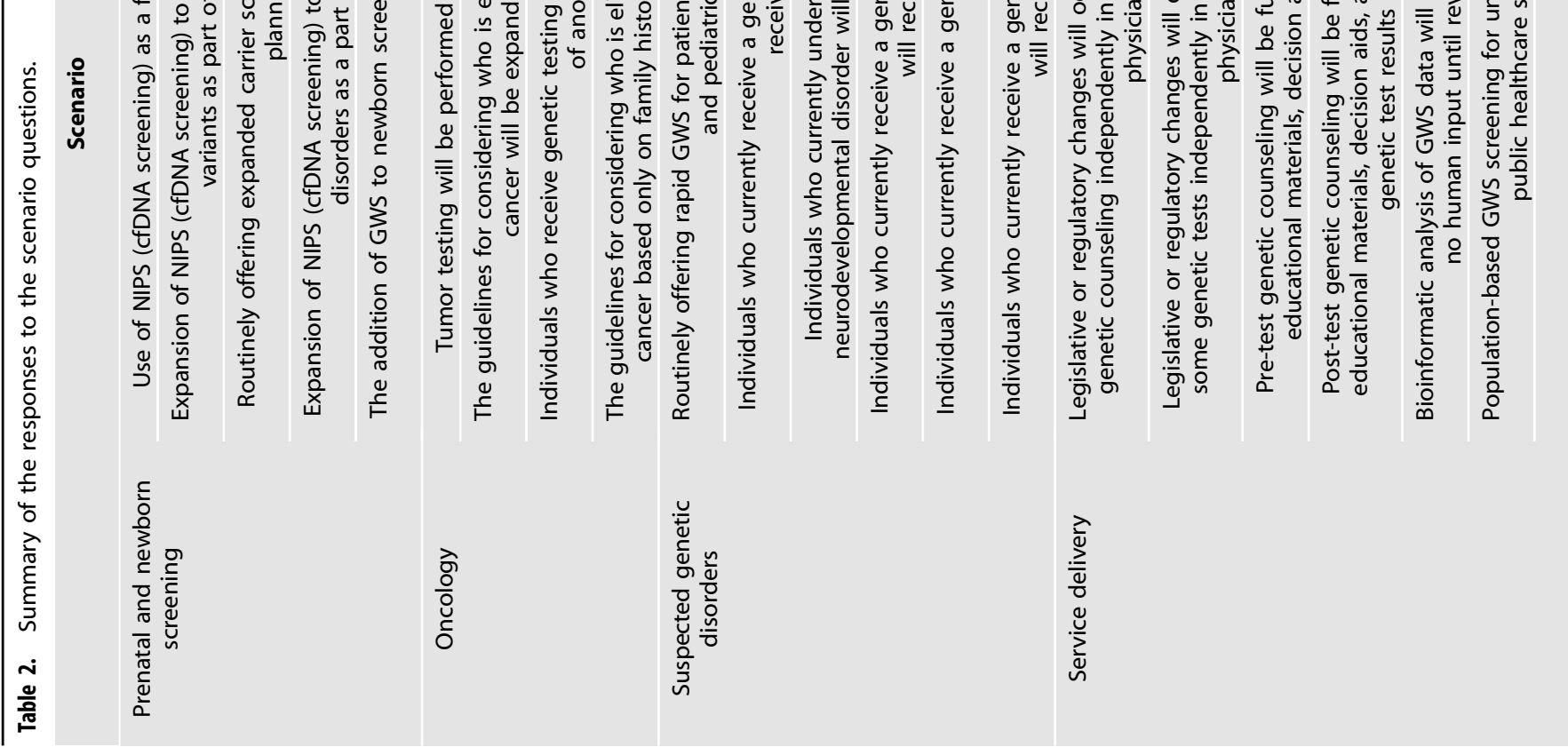


in expectations about the use of GWS as a diagnostic tool as compared to a screening tool could be due to concerns about clinical utility and sustainability, as well as some of the complex medical and ethical issues that can arise from broad screening approaches $[13,37]$. Another key finding was the expectations regarding growth in utilization in many clinical areas, including broader use of carrier screening in preconception settings and expanding the eligibility guidelines for genetic testing/counseling to include all types of cancer for those affected with or at-risk for hereditary cancer. The potential impact of this expected growth in need on the genetic workforce will be exacerbated by the expected substitution of GWS for current methods of genetic testing because GWS require more provider time per case than multigene panels or CMA [38]. This dynamic is likely to place a strain on the already small clinical genetic workforce in Canada, which is composed of $\sim 450$ genetic counselors (1.2 per 100,000 Canadians) and 111 clinical geneticists ( 0.3 per 100,000 Canadians) [39-41], not all of whom work in direct patient-facing roles [42]. Indeed, the need for genetic services in Canada is already outpacing what the system is able to provide, which has led to long wait times and high caseloads for clinical genetic providers $[3,42]$. For example, wait times under current conditions can be up to 496 days in Nova Scotia and 700 days in Ontario for nonurgent appointments $[3,43]$. If the eligibility criteria for hereditary cancer services expand as predicted by our participants, even longer wait times are likely unless substantial changes occur in service delivery models. As universal access to essential medical services is a core principle of the Canadian health system, the survey findings highlight the urgent need for health human resource planning for clinical genetic and genomic services to provide adequate access for all individuals who need them.

Concerns about the future shortage of the human resources required to meet expanding needs have also prompted discussions on the potential use of alternative service delivery models. Genetic counselors are currently unregulated in Canada, other than in specific institutions or provinces which have a delegation model of legal recognition in specific settings [44]. In our Delphi results, regulatory changes that would allow genetic counselors to provide genetic counseling or order some tests independently were seen as likely by about half of respondents, many of whom were genetic counselors, but there was support from other genetics professionals. These regulatory changes may reduce the workforce strain and could also increase access by expanding the roles of genetic counselors beyond tertiary care centers, which is where the majority of clinical genetic services are currently provided in Canada.

Participants were asked their perspectives on changes in service delivery models arising from technological innovations such as the automation of tasks. These technological innovations may mitigate the issue of increased provider time needed for more complex genomic testing, by reducing the face-to-face appointment time or by streamlining the time needed for patient-related activities or administrative tasks. However, it is also possible that there will be disruptive technological innovations over the next 10 years that will impact service delivery that were not captured by our survey. For example, we opted to not include any questions about telemedicine because there is limited evidence evaluating the impacts of telemedicine on resource efficiency gains including human resources [45]. However, the uptake and utilization of telemedicine have dramatically increased during the COVID-19 pandemic [46-49] and it is possible that virtual care could fundamentally change service delivery in clinical genetics.

Our study had several limitations that are worth discussing. Although there is some debate in the literature about the appropriateness of using the Delphi method as a means of determining expert consensus, we sought to overcome some of these critiques by having a heterogeneous panel, blinding participants to the identities and individual responses of other 
Table 3. Summary of the responses to the percent-style questions on Survey \#1 and \#2.

\begin{tabular}{|c|c|c|c|c|c|c|c|c|}
\hline & Scenario & Survey\# & $n$ & Mean (SD) & Median & $\begin{array}{l}\text { I do not } \\
\text { know (n) }\end{array}$ & Range & $p$ value $^{b}$ \\
\hline \multirow{5}{*}{ Oncology } & $\begin{array}{l}\text { The percentage of individuals with any type of } \\
\text { cancer who will receive germline } \\
\text { pharmacogenetic testing to inform their } \\
\text { treatment options }\end{array}$ & 2 & 14 & $59(24.5)^{\mathrm{a}}$ & 55 & 4 & $25-100$ & \\
\hline & \multirow{2}{*}{$\begin{array}{l}\text { The percentage of individuals who receive } \\
\text { tumor testing who will receive GWS }\end{array}$} & 1 & 25 & $44(26.4)$ & 50 & 9 & $8-100$ & 0.94 \\
\hline & & 2 & 14 & $48(24.1)$ & 45 & 4 & $15-97$ & \\
\hline & \multirow{2}{*}{$\begin{array}{l}\text { The percentage of individuals who receive } \\
\text { genetic testing for hereditary cancer who will } \\
\text { receive GWS }\end{array}$} & 1 & 24 & 27 (23.6) & 19.5 & 9 & $0-75$ & 0.40 \\
\hline & & 2 & 16 & $32(17.7)$ & 30 & 2 & $10-80$ & \\
\hline \multirow{2}{*}{$\begin{array}{l}\text { Suspected } \\
\text { genetic } \\
\text { disorders }\end{array}$} & \multirow{2}{*}{$\begin{array}{l}\text { The percentage of pediatric patients with a } \\
\text { suspected genetic disorder who will be offered } \\
\text { GWS as their first-line genetic investigation }\end{array}$} & 1 & 25 & $55(28.3)$ & 50 & 1 & $10-100$ & 0.26 \\
\hline & & 2 & 14 & $58(23.3)$ & 60 & 1 & $15-100$ & \\
\hline
\end{tabular}

The questions are ranked from highest mean to lowest mean on Survey \#2 within each content area. Those who chose "I do not know" were excluded from the mean calculation. One respondent's answers were omitted from the final analysis.

GWS genome-wide sequencing (exome or genome sequencing).

aThis item did not meet the stability definition, the mean changed by $>15 \%$ from survey \#1 to survey \#2.

$\mathrm{b}_{p}$ value comparing means from Survey \#1 and Survey \#2 using paired-samples $t$ test.

respondents, and having multiple measures of agreement with a focus on stability rather than consensus [19]. The size of our Delphi panel (27 and 18 participants answered Survey \#1 and \#2 respectively) may not have been large enough to fully represent the breadth of perspectives across Canadian provinces. However, our study size was in keeping with other Delphi panels; a systematic review of Delphi studies reported that in the final round of the process over half of the studies had sample sizes under 25 participants [30]. As with other aspects of the Delphi method, there is no best practice for determining the sample size required to represent the breadth of expert perspectives.

In addition, results might have been impacted by participants providing their perspectives on a range of topics, not only those related to their current area of practice, and by an overrepresentation of participants working in British Columbia (possibly because they were positively disposed to respond to a survey from local researchers). Although we aimed to capture a heterogeneous sample with our sampling framework, those who chose to participate in the study may not be representative of the entire Canadian workforce, granting a careful consideration of potential sources of recruitment bias when bigger samples are available. Of note, we had few individuals who identified as laboratory geneticists or $\mathrm{PhD}$ geneticists participate in our study, and since these individuals are not typically working in direct patient care roles, their views about the broad implementation of some of these scenarios may have been different than those who are more clinically focused. Owing to their different setting and expertise, there is the need for perspectives of laboratory personnel to be included in health policy decisions.

Finally, it is difficult to determine what considerations may have factored into participants' responses, given that our questions were framed in terms of expected broad implementation in the respondent's jurisdiction by 2030 . This framing was intended to inform workforce planning for the next decade, but we do not know what other factors such as geographic location or aversion towards risk might have influenced respondents when they considered expected utilization, uptake, reimbursement, and clinical utility in the next 10 years.

\section{CONCLUSION}

The results from this study may be used to inform health human resource planning for clinical genetic and genomic services. Our results provide useful evidence to identify a range of plausible futures that ought to be considered in strategic planning and should be informative for administrators and policymakers across high-income countries who are engaged in priority-setting for the future need for clinical genetic and genomic services. Our study adds to the existing knowledge about the perspectives of genetic professionals on the future trends in the utilization and service delivery of clinical genetic services in Canada. Future research in this area could include eliciting perspectives from a broader group of stakeholders including patient groups, policymakers, and specifically targeting genetic professionals who are involved in laboratory or industry settings. There may also be value in conducting qualitative research in this area by using interviews and focus groups to deepen our understanding of expert opinions about the future of genetic services.

\section{DATA AVAILABILITY}

All data generated through the study are reported in aggregate form within the manuscript. Respondent-level data will not be made available to protect the anonymity of respondents.

\section{REFERENCES}

1. Greenberg SE, Boothe E, Delaney CL, Noss R, Cohen SA. Genetic counseling service delivery models in the United States: Assessment of changes in use from 2010 to 2017. J Genet Couns. 2020;29:1126-41.

2. Dragojlovic N, Borle K, Kopac N, Ellis U, Birch P, Adam S, et al. The composition and capacity of the clinical genetics workforce in high-income countries: a scoping review. Genet Med. 2020;22:1437-49. 
3. Cancer Care Ontario. Recommendation Report for Ontario's Clinical Genetic Services [Internet]. 2018. Available from: https://www.cancercareontario.ca/sites/ ccocancercare/files/assets/ClinicalGeneticServicesRecommendationReport.pdf.

4. Concert Genetics. The current landscape of genetic testing [Internet]. 2018. Available from: https://www.concertgenetics.com/resources/2018-currentlandscape-genetic-testing/.

5. Lionel AC, Costain G, Monfared N, Walker S, Reuter MS, Hosseini SM, et al. Improved diagnostic yield compared with targeted gene sequencing panels suggests a role for whole-genome sequencing as a first-tier genetic test. Genet Med. 2018;20:435-43.

6. Dragojlovic N, Kopac N, Borle K, Tandun R, Ellis SS, Birch P, et al. Utilization and uptake of clinical genetics services in high-income countries: a scoping review. Health Policy. 2021;125:877-87.

7. Adam S, Birch PH, Coe RR, Bansback N, Jones AL, Connolly MB, et al. Assessing an interactive online tool to support parents' genomic testing decisions. J Genet Couns. 2019;28:10-7.

8. Zierhut HA, Macfarlane IM, Ahmed Z, Davies J. Genetic counselors' experiences and interest in telegenetics and remote counseling. J Genet Couns. 2018;27:329-38

9. Schmidlen T, Schwartz M, DiLoreto K, Kirchner HL, Sturm AC. Patient assessment of chatbots for the scalable delivery of genetic counseling. J Genet Couns. 2019;28:1166-77.

10. Birch S, Kephart G, Murphy GT, O'Brien-Pallas L, Alder R, MacKenzie A. Health human resources planning and the production of health: development of an extended analytical framework for needs-based health human resources planning. J Public Health Manag Pract. 2009;15:56-61.

11. Sorscher S. Universal multigene panel testing in all breast cancer patients. Am J Med. 2019;132:e765-6.

12. Beitsch PD, Whitworth PW. Can breast surgeons provide breast cancer genetic testing? An American Society of Breast Surgeons survey. Ann Surg Oncol. 2014:21:4104-8.

13. Brothers KB, Vassy JL, Green RC. Reconciling opportunistic and population screening in clinical genomics. Mayo Clin Proc. 2019 ;94:103-9.

14. Green ED, Gunter C, Biesecker LG, Di Francesco V, Easter CL, Feingold EA, et al. Strategic vision for improving human health at The Forefront of Genomics. Nature 2020;586:683-92.

15. Stevens B, Krstic N, Jones M, Murphy L, Hoskovec J. Finding middle ground in constructing a clinically useful expanded carrier screening panel. Obstet Gynecol. 2017;130:279-84.

16. Sullivan W, Payne K. The appropriate elicitation of expert opinion in economic models. Pharmacoeconomics 2011;29:455-9.

17. Nowack M, Endrikat J, Guenther E. Review of Delphi-based scenario studies: quality and design considerations. Technol Forecast Soc Change. 2011;78:1603-15.

18. Van Der Helm R. Towards a clarification of probability, possibility and plausibility: How semantics could help futures practice to improve. Foresight 2006;8:17-27.

19. Jorm AF. Using the Delphi expert consensus method in mental health research. Aust N Z J Psychiatry. 2015;49:887-97.

20. Hasson F, Keeney S, McKenna H. Research guidelines for the Delphi survey technique. J Adv Nurs. 2000;32:1008-15.

21. Skulmoski G, Hartman FT, Krahn J. The Delphi method for graduate research. J Inf Technol Educ. 2007;6:1-21.

22. Fink-Hafner $D$, Dagen $T$, Doušak $M$, Novak $M$, Hafner-Fink $M$. Delphi method: Strengths and weaknesses. Metod Zv. 2019;16:1-19.

23. Kohler JN, Turbitt E, Lewis KL, Wilfond BS, Jamal L, Peay $\mathrm{HL}$, et al. Defining personal utility in genomics: a Delphi study. Clin Genet. 2017;92:290-7.

24. Scheuner MT, Russell MM, Chanfreau-Coffinier C, Peredo J, Yano EM, Hamilton AB, et al. Stakeholders' views on the value of outcomes from clinical genetic and genomic interventions. Genet Med. 2019;21:1371-80.

25. Payne K, Nicholls SG, McAllister M, MacLeod R, Ellis I, Donnai D, et al. Outcome measures for clinical genetics services: a comparison of genetics healthcare professionals and patients' views. Health Policy. 2007;84:112-22.

26. Harris PA, Taylor R, Thielke R, Payne J, Gonzalez N, Conde JG. Research electronic data capture (REDCap)-a metadata-driven methodology and workflow process for providing translational research informatics support. J Biomed Inf. 2009:42:377-81.

27. Dajani JS, Sincoff MZ, Talley WK. Stability and agreement criteria for the termination of Delphi studies. Technol Forecast Soc Change. 1979;13:83-90.

28. Linstone HA, Turoff M (eds). The Delphi method: Techniques and applications. Reading, MA: Addison-Wesley; 1975.

29. Trevelyan EG, Robinson N. Delphi methodology in health research: How to do it? Eur J Integr Med. 2015;7:423-8.

30. Diamond IR, Grant RC, Feldman BM, Pencharz PB, Ling SC, Moore AM, et al. Defining consensus: a systematic review recommends methodologic criteria for reporting of Delphi studies. J Clin Epidemiol. 2014;67:401-9.
31. Braun V, Clarke V. Using thematic analysis in psychology. Qual Res Psychol. 2006;3:77-101.

32. Clark MM, Hildreth A, Batalov S, Ding Y, Chowdhury S, Watkins K, et al. Diagnosis of genetic diseases in seriously ill children by rapid whole-genome sequencing and automated phenotyping and interpretation. Sci Transl Med. 2019;11: eaat6177.

33. Johansen Taber KA, Beauchamp KA, Lazarin GA, Muzzey D, Arjunan A, Goldberg JD. Clinical utility of expanded carrier screening: results-guided actionability and outcomes. Genet Med. 2019;21:1041-8.

34. Li C, Vandersluis S, Holubowich C, Ungar WJ, Goh ES, Boycott KM, et al. Costeffectiveness of genome-wide sequencing for unexplained developmental disabilities and multiple congenital anomalies. Genet Med. 2021;23:451-60.

35. Waddell K, Wilson M. Rapid synthesis: examining the public provision and funding of clinical genetic tests. Hamilton, Canada (McMaster Health Forum, 2017).

36. Friedman JM, Cornel MC, Goldenberg AJ, Lister KJ, Sénécal K, Vears DF. Genomic newborn screening: public health policy considerations and recommendations. BMC Med Genomics. 2017;10:13-20.

37. Murray MF, Giovanni MA, Doyle DL, Harrison SM, Lyon E, Manickam K, et al. DNAbased screening and population health: a points to consider statement for programs and sponsoring organizations from the American College of Medical Genetics and Genomics (ACMG). Genet Med. 2021;23:989-95.

38. Nisselle A, Macciocca I, McKenzie F, Vuong H, Dunlop K, McClaren B, et al Readiness of clinical genetic healthcare professionals to provide genomic medicine: an Australian census. J Genet Couns. 2019;28:367-77.

39. Costa T, Gillies B, Oh T, Scott J. The Canadian genetic counseling workforce: perspectives from employers and recent graduates. J Genet Couns. 2021;30:406-17.

40. National Society of Genetic Counselors. Professional Status Survey 2018: Demographics and methodology. 2018.

41. Canadian Medical Association. Medical Genetics Profile [Internet]. Available from: https://www.cma.ca/sites/default/files/2019-01/medical-genetics-e.pdf (2019).

42. National Society of Genetic Counselors. Professional Status Survey 2020: Canada. 2020 .

43. Government of Nova Scotia. Nova Scotia Wait times [Internet]. Available from: https://waittimes.novascotia.ca/procedure/genetic-consultation\#waittimes-90 (2021).

44. Patrinos D, Caron R, Maria B. Genetic counsellors, legal recognition, and the road less travelled. McGill J Law Heal Rev droit Sté McGill. 2020;14:109-58.

45. Gorrie A, Gold J, Cameron C, Krause M, Kincaid H. Benefits and limitations of telegenetics: a literature review. J Genet Couns. 2021;30:924-37.

46. Ahimaz $P$, Giordano J, Disco M, Harrington E, Levinson E, Spiegel E, et al. COVID contingencies: early epicenter experiences of different genetics clinics at a New York City institution inform emergency adaptation strategies. J Genet Couns. 2021;30:938-48.

47. Mauer C, Zimmerman J, Lahiri S, Watson E, Parsi L, Berg J, et al. Adapting genetic counseling operations amidst the COVID-19 pandemic. J Genet Couns. 2021;30:949-55.

48. Shannon KM, Emmet MM, Rodgers LH, Wooters M, Seidel ML. Transition to telephone genetic counseling services during the COVID-19 pandemic. J Genet Couns. 2021;30:984-8.

49. Mills R, MacFarlane IM, Caleshu C, Ringler MA, Zierhut HA. Genetic counselor experiences with telehealth before and after COVID-19. J Genet Couns. 2021;30:999-1009.

\section{ACKNOWLEDGEMENTS}

The GenCOUNSEL Study is led by Alison M. Elliott, Jehannine Austin, Bartha Knoppers, and Larry D. Lynd with Project Manager Alivia Dey, and includes the following coinvestigators: Shelin Adam, Nick Bansback, Patricia Birch, Lorne Clarke, Nick Dragojlovic, Jan Friedman, Debby Lambert, Daryl Pullman, Alice Virani, Wyeth Wasserman, and Ma'n Zawati.

\section{FUNDING}

GenCOUNSEL was funded through the Large Scale Applied Research Project (LSARP) Genome Canada competition with co-funding from Canadian Institute for Health Research (CIHR), Genome BC, Genome Quebec, Provincial Health Services Authority, BC Children's Hospital Foundation, and BC Women's Hospital Foundation.

\section{COMPETING INTERESTS}

The authors declare no competing interests. 


\section{ETHICS DECLARATION}

This study was approved by the University British Columbia Research Ethics Board as a sub-study of the GenCOUNSEL research project (REB ID: H19-00427).

\section{ADDITIONAL INFORMATION}

Supplementary information The online version contains supplementary material available at https://doi.org/10.1038/s41431-021-01017-2.
Correspondence and requests for materials should be addressed to Larry D. Lynd. Reprints and permission information is available at http://www.nature.com/ reprints

Publisher's note Springer Nature remains neutral with regard to jurisdictional claims in published maps and institutional affiliations. 